\title{
PLUME MEASUREMENT AND MODELING RESULTS FOR A XENON HOLLOW CATHODE
}

\author{
Mark W. Crofton ${ }^{\dagger}$ \\ The Aerospace Corporation, El Segundo, California 90245-4691 \\ and \\ Iain D. Boyd ${ }^{\&}$ \\ University of Michigan, Ann Arbor, Michigan 48109-2140
}

\begin{abstract}
$\underline{\text { Abstract }}$
Behavior of the xenon dispenser hollow cathode is complex, exhibiting high through-anode ion emission, unusual particle energy distributions, and high plume erosion rates. The device may find new application as an ion micro-thruster. A flight-type hollow cathode was characterized using several diagnostic methods. Measurements involved a retarding potential analyzer, quadrupole mass spectrometer, and Langmuir probe. The far-field energy, flux, and charge state distributions of plume ions were studied as a function of cathode keeper current, flow rate, and viewing angle. The study of ion energy dependence on charge state is the first for a xenon hollow cathode. The results provide strong evidence in support of ion acceleration by a potential hill mechanism. The plume expansion was modeled by explicitly including both electrons and heavy particles in a combined Particle In Cell and direct simulation Monte Carlo approach. Reasonable comparisons were generally possible, but where broad ion energy distributions were measured they were not well matched by the simulations.
\end{abstract}

\section{Nomenclature}

$\begin{array}{ll}\mathrm{A} & \text { ampere } \\ \mathrm{d} & \text { keeper-extractor separation } \\ \mathrm{E} & \text { kinetic energy } \\ \mathrm{F} & \text { flow rate, } \mathrm{mg} / \mathrm{s} \\ \mathrm{I}_{\mathrm{ck}} & \text { cathode keeper current, Ampere } \\ \mathrm{I}_{\mathrm{h}} & \text { cathode heater current, Ampere } \\ \mathrm{m} & \text { particle mass, atomic mass units } \\ \mathrm{q} & \text { ion charge (=ze) } \\ \mathrm{T} & \text { temperature, } \mathrm{K} \\ \mathrm{T}_{\mathrm{i}} & \text { ion temperature, eV } \\ \mathrm{T}_{\mathrm{e}} & \text { electron temperature, eV } \\ \mathrm{V}_{\mathrm{cb}} & \text { cathode body potential, Volts } \\ \mathrm{V}_{\mathrm{ck}} & \text { cathode keeper potential, referenced to the } \\ & \text { cathode body, Volts }\end{array}$

$\mathrm{V}_{\mathrm{r}} \quad$ repeller potential of the RPA, Volts

$\mathrm{Z} \quad$ ion charge number

$\phi \quad$ angle between RPA normal and plume axis

$\theta \quad$ angle between QMS normal and plume axis

\section{$\underline{\text { Introduction }}$}

Hollow cathodes are of general technological importance. One application is in electric thruster systems, where they serve as critical components providing an efficient source of electrons. Xenon hollow cathodes can produce single-point failures in ion engines and Hall effect thrusters, and they are an important factor regarding erosion of the screen grid and other components in ion engines. During operation at the high emission current required for high-power ion propulsion systems, the orifice and any components in the plume erode rapidly. ${ }^{1}$ Ions of sufficient energy and flux to cause significant erosion have been observed in plume experiments. ${ }^{2-4}$

The mechanism by which the high-energy ions arise is not established, but two principal hypotheses have been previously put forward. One mechanism invokes the formation of a potential hill a few $\mathrm{mm}$ downstream from the orifice. ${ }^{3,6}$ Although consistent with some of the data, no clear understanding has emerged of the means by which a hill of sufficient height could be formed. An alternative mechanism has been postulated whereby the current density at the orifice (on the order of $10^{4} \mathrm{~A} \mathrm{~cm}^{-2}$ ) results in ion acceleration via a magnetohydrodynamic effect. ${ }^{2,7}$

A third hypothesis concerning the formation of high-energy ions has been applied to vacuum arc plasmas, where acceleration of ions also occurs in the direction away from the cathode and E/q can be much greater than the applied voltage. In this case a gas dynamic model is invoked that describes ion acceleration as driven by pressure gradients and electron-ion friction. ${ }^{8,9}$ According to this approach, a

\footnotetext{
†Research Scientist, Laboratory Operations/Space Materials Laboratory, M5-754, P.O. Box 92957, Los Angeles, CA 900092957. Member AIAA.

\&Associate Professor, Department of Aerospace Engineering, 1320 Beal Avenue. Member AIAA.

Copyright (C) 2002 by The Aerospace Corporation. Published by the American Institute of Aeronautics and Astronautics, Inc. with permission.
} 
small potential hump may exist as a consequence of plasma acceleration rather than as its cause. In the gas dynamic model ion energy distribution is independent of charge state.

Spatially-resolved experimental measurements of electric potential and the ion velocities near a hollow cathode orifice have previously been performed. ${ }^{10} \mathrm{~A}$ prominent potential hill was not found in either the Langmuir probe or laser-induced fluorescence measurements. The measured velocity distribution near the hollow cathode test articles depended strongly on the cathode type and/or operating point, including plume-mode vs. spot-mode operation.

In the present study, a retarding potential analyzer (RPA) and a quadrupole mass spectrometer (QMS) were used in conjunction. The QMS provided a simple means of monitoring ions according to $\mathrm{m} / \mathrm{q}$, and easily resolved the charge states of xenon. In addition, a Langmuir probe spot measurement was made in the plume. A computational model has been developed to simulate hollow cathode plume behavior at the particle level. Comparisons between model results and the experimental data have been made.

The subject of the present study is a flight-type xenon hollow cathode originally developed for use as the main cathode of the UK-10 ion engine. Due to reliability problems discovered during endurance testing, the UK-10 thrusters on the Artemis spacecraft were launched with substantially redesigned hollow cathodes. The present cathode will be referred to as the T5 cathode, after the engineering model of the UK-10 ion thruster.

Measurements of the ion kinetic-energy distribution in the far-field have been performed on other cathodes with a retarding potential analyzer (RPA) or an energy analyzer, ${ }^{2-4}$ and more recently on the T5 cathode with an RPA and a quadrupole mass spectrometer (QMS). ${ }^{5}$ The early results revealed that a very broad energy distribution exists in the high current regime. The data indicate that ions are abundantly formed and emitted through-anode with energies as much as several times higher than $\mathrm{eV}_{\mathrm{ck}}$ even though the anode potential is above the cathode by $\left|\mathrm{V}_{\mathrm{ck}}\right|$. Unfortunately, RPA and energy analyzer devices do not distinguish between xenon ions with different charge states but the same E/q (=E/ze).

The presence of abundant doubly-charged ions was discovered through the QMS measurements. ${ }^{5}$ The higher charge states will contribute significantly to the erosive power of the hollow cathode plume, and be dominant over $\mathrm{Xe}^{+}$at relatively low flux levels. In addition, $\mathrm{Xe}^{2+}$ presence in abundance demonstrates a higher fraction of ionization than had previously been assumed. High fractional ionization may be a factor in the creation of a plasma potential that exceeds the anode voltage. A role might also exist for multiple- charge ions in the production of energetic species with lower charge states.

Most previous hollow cathode characterization studies have incorporated a large anode shell and a secondary discharge between the cathode and this anode to simulate the ion engine environment. Such an approach complicates the study of the hollow cathode plume since the external discharge may affect the measured results. The hollow cathode was operated in a stand-alone configuration in the present study.

As a thruster component hollow cathodes are much simpler to build and operate than the systems in which they are incorporated. Hollow cathodes will make attractive stand-alone ion thrusters if the ion emission current and device efficiency can become more comparable to existing ion thruster systems. The simplicity and small physical volume of hollow cathodes are attractive features for micro-satellite or nano-satellite propulsion applications that may require the high specific impulse of ion propulsion. Behavior of hollow cathodes is complex, however, and poorly understood. An understanding of hollow cathode behavior is helpful to aid its development as a standalone ion thruster and as an optimized thruster component.

\section{$\underline{\text { Experimental }}$}

A xenon hollow cathode was installed in a $75-\mathrm{cm}-$ diameter vacuum chamber, pumped by a $1000 \mathrm{l} / \mathrm{s}$ (on nitrogen) turbomolecular pump and a 12,500/4,500/ 1,000 l/s (hydrogen/water/xenon) TMP150 cryopump (CVI) mounted on a 10-in. conflat flange. ${ }^{11}$ The cryopump could be readily isolated from the chamber by an 8 in. electropneumatic gate valve. The base pressure with no xenon flow was about $2 \times 10^{-7}$ Torr. With xenon flow rate of $0.105 \mathrm{mg} / \mathrm{s}$, the background pressure indicated by an ion gauge positioned far from the cryopump was about $1.5 \times 10^{-5}$ Torr, after applying a standard sensitivity correction for xenon. The ion gauge was located well above and behind the hollow cathode orifice, at a distance of more than $40 \mathrm{~cm}$.

The test article was originally designed for use as the main cathode in the UK-10 ion engine. An engineering model of the UK-10, designated T5, has been well-characterized. ${ }^{12}$ The cathode was installed on a rotatable table, with a QMS positioned behind a fixed beam skimmer, and the RPA also viewing the plume near the orifice (see Fig. 1). The range of rotary motion for the hollow cathode was $-50 \mathrm{deg}$. to $+90 \mathrm{deg}$. with respect to the axis of the QMS. The 5-mm aperture of the grounded skimmer was about $25 \mathrm{~mm}$ downstream from the keeper orifice. The entrance of the QMS was either $22 \mathrm{~cm}$ or $48 \mathrm{~cm}$ further downstream, and aligned with the hollow cathode orifice and beam skimmer. The 
longer distance applies to a differential pumping configuration. For some of the measurements, differential pumping was implemented to lower the background pressure in the region between QMS and skimmer. The pressure in the QMS region was about 100 times less than the main chamber pressure when $\theta$ was large, and about 7 times less for $\theta=0$ degrees. For data obtained without differential pumping the QMS and main chamber regions were not isolated, and their pressures were approximately equal. In the present study, the QMS was always operated with detector on and ionizer turned off.

The RPA consisted of a Faraday cup (Kimball Physics, FC-72A) with four closely spaced grids at the input. The entrance and third grid were grounded, and the fourth or innermost was biased negative to reject plasma electrons and to suppress the loss of secondary electrons. The second grid operated at the retarding potential, $\mathrm{V}_{\mathrm{r}}$. The acceptance area of the entrance aperture was $1.0 \mathrm{~cm}^{2}$, and each of the grid apertures was covered with a fine tungsten mesh. The aperture was located $21 \mathrm{~cm}$ from the cathode orifice.

A second configuration involving the QMS was utilized to perform the measurements of ion energy distribution vs. charge state; a retarding electrode was placed just downstream from the grounded exit plane of the skimmer. The QMS entrance was approximately $108 \mathrm{~cm}$ from the skimmer aperture. By tuning the QMS to the transmission peak for a particular charge state, RPA data were obtained with detection of a single ion species. Signal was obtained directly from the QMS channeltron and processed with a pulse counter.

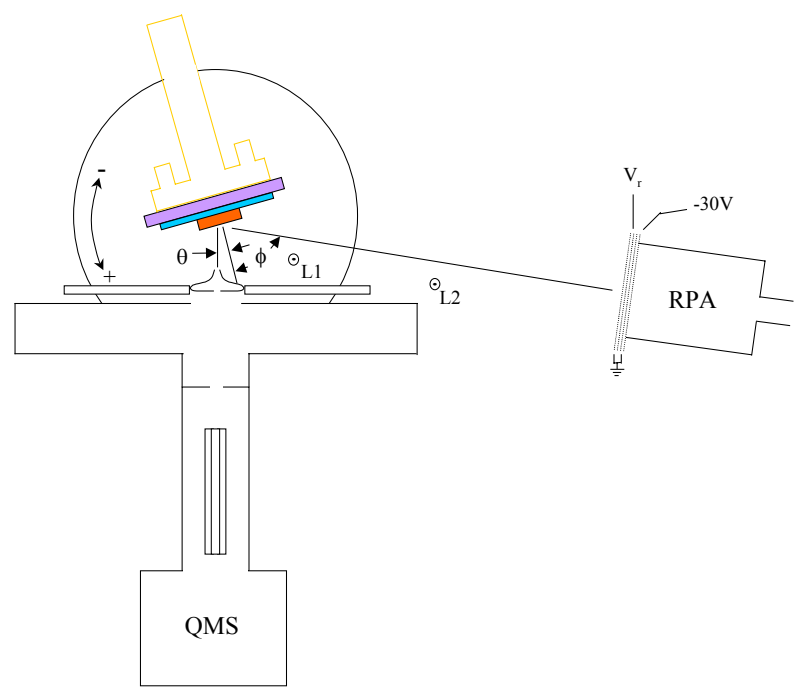

Figure 1. Schematic of the experimental setup, top view.

Two Langmuir probes constructed with 1-mm tungsten wire and shielded with ceramic insulator, were mounted vertically in the plume. The probes, designated L1 and L2 in Fig. 1, were placed at approximately 35 and $110 \mathrm{~mm}$, respectively, from the keeper. In each case a 3-mm length of the tungsten wire was exposed to the plume.

The hollow cathode contained an impregnated tungsten dispenser, $1.0 \mathrm{~mm}$ i.d. $\times 2.8 \mathrm{~mm}$ o.d. $\times 11 \mathrm{~mm}$, which acts as a chemical factory to release barium to

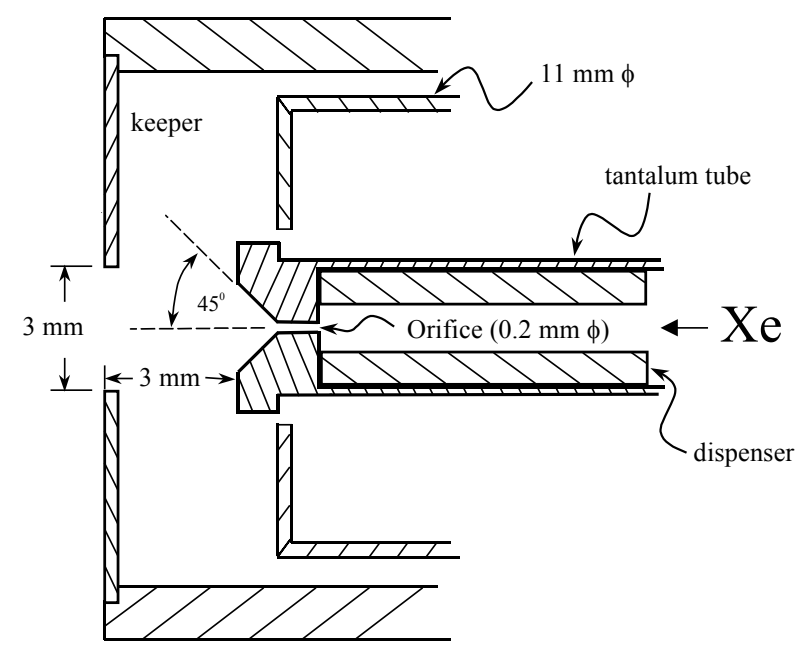

Figure 2. Schematic cross section of the nozzle/keeper configuration, approximately to scale. Heater, radiation shield, and other items not shown.

the surface at an appropriate rate to achieve low work function and long life. The dispenser must be at approximately $1000{ }^{\circ} \mathrm{C}$ for the cathode to operate normally. The orifice of the hollow cathode, machined out of solid tantalum, was $0.2 \mathrm{~mm}$ in diameter $\times 1.0$ $\mathrm{mm}$ long, with a downstream full-angle chamfer of 90 degrees (see Fig. 2). A keeper electrode with 3-mmdiameter aperture was positioned just downstream in an enclosed configuration. The hollow cathode had been operated previously. ${ }^{5,13}$ For the present study the device was run at a number of different operating points (see Table 1).

The cathode to anode voltage, $\mathrm{V}_{\mathrm{ck}}$, was always under $35 \mathrm{~V} . \mathrm{V}_{\mathrm{ck}}$ depends on the cathode temperature, flow rate, $\mathrm{I}_{\mathrm{ck}}$ (which influences cathode temperature), and presumably the condition of the dispenser, size of the orifice and other details of the geometry. At high temperature, such as normally obtained upon startup but prior to shutdown of the cathode heater, $V_{\mathrm{ck}}$ can be substantially below $20 \mathrm{~V}$.

The cathode discharge current was never set higher than $2.8 \mathrm{~A}$. This limit was due to concerns about the high power level and orifice erosion, as well as constraints in maximum obtainable current determined by flow rate and cathode temperature. The discharge current could generally be increased if heater current 
was supplied (up to $2.0 \mathrm{~A}$, the typical current required for discharge initiation) while the discharge was on. The highest discharge current levels could only be achieved at the higher flow rates, however.

Changes in the operating point required a settling period, during which the device came to a static condition. The duration of this period was typically 10 to 15 minutes, but in some cases substantially longer. The underlying cause of the settling behavior is believed to be a long time constant for returning to the set flow rate through the orifice. This phenomenon in itself provides some indication of the unusual nature of this type of hollow cathode.

\section{$\underline{\text { Model Description }}$}

Models of hollow cathode plumes have been developed by Parks et $\mathrm{al}^{14}$ and by Williams and Wilbur. ${ }^{15}$ In Ref. 14, a fluid model of the electrons combined with an assumed profile for the ion density was used to model a mercury hollow cathode. By assuming anomalously low electrical conductivity (reduced by a factor of about 1000), good agreement was obtained for measurements of plasma potential and electron temperature.

The model under development in this work seeks to go beyond that described in Ref. 14 by explicitly modeling both the electrons and the heavy particles (ions and neutrals). Due to the low density nature of the hollow cathode plumes, a kinetic, particle approach is employed to simulate the xenon ions and neutral atoms. A detailed fluid model of the electrons is also employed.

The ions and neutrals are treated using a combination of the Particle In Cell method (PIC) ${ }^{16}$ for transporting the ions in electrostatic fields, and the direct simulation Monte Carlo method (DSMC) ${ }^{17}$ for performing collisions and transporting the neutral atoms. Momentum transfer and charge exchange collisions are the only collision mechanisms implemented at this stage.

The spatial distribution of ions gives the electron number density under the assumption of charge neutrality. Solution of the electron continuity equation then provides the electron velocity, $\mathbf{v}_{\mathrm{e}}$. The electron momentum equation is given by: ${ }^{18}$

$\frac{\partial}{\partial t}\left(m_{e} n_{e} \mathbf{v}_{e}\right)+m_{e} n_{e}\left(\mathbf{v}_{e} \cdot \nabla\right) \mathbf{v}_{e}=-e n_{e} \mathbf{E}-\nabla p_{e}+\mathbf{R}$

where $m_{e}$ is the mass of an electron, $n_{e}$ is the electron number density, $v_{\mathrm{e}}$ is the electron velocity vector, $\mathbf{E}$ is the electric field, $\mathrm{p}_{\mathrm{e}}$ is the electron pressure, and $\mathbf{R}$ is the friction term. It is further assumed that the electrons behave as a perfect gas $\left(\mathrm{p}_{\mathrm{e}}=\mathrm{n}_{\mathrm{e}} \mathrm{kT} \mathrm{T}_{\mathrm{e}}\right)$, and that the friction term is given by:

$$
\mathbf{R}=\frac{e n_{e} \mathbf{j}}{\sigma}
$$

where $\mathbf{j}$ is the current density, and $\sigma$ is the electrical conductivity.

Assuming a steady state, neglecting the inertial term on the left hand side of Eq. (1), and introducing the plasma potential $-\nabla \phi=\mathbf{E}$, a generalized Ohm's law is obtained:

$$
\mathbf{j}=\sigma\left\lfloor-\nabla \phi+\frac{1}{e n_{e}} \nabla\left(n_{e} k T_{e}\right)\right\rfloor
$$

The charge continuity condition with source term $\mathrm{S}_{\mathrm{e}}$ due to ionization:

$$
\nabla \cdot \mathbf{j}=S_{e}
$$

is then solved to obtain the plasma potential. This equation is written as a Laplace equation with weak source terms and is solved using an Alternating Direction Implicit (ADI) scheme.

The electron energy equation is given by: ${ }^{18}$

$$
\begin{aligned}
& \frac{\partial}{\partial t}\left(\frac{3}{2} n_{e} k T_{e}\right)+\frac{3}{2} n_{e}\left(\mathbf{v}_{e} \cdot \nabla\right) k T_{e}+p_{e} \nabla \cdot \mathbf{v}_{e}= \\
& \nabla \cdot \kappa_{e} \nabla T_{e}+\mathbf{j} \cdot \mathbf{E}-3 \frac{m_{e}}{m_{i}} v_{e} n_{e} k\left(T_{e}-T_{H}\right)
\end{aligned}
$$

where $\mathrm{m}_{\mathrm{i}}$ is the ion mass, $v_{\mathrm{e}}$ is the total electron collision frequency, $\kappa_{\mathrm{e}}$ is the electron thermal conductivity, and $\mathrm{T}_{\mathrm{H}}$ is the heavy particle temperature. Again assuming a steady state, and neglecting the collision term as small:

$\kappa_{e} \nabla^{2} T_{e}=-\nabla \cdot \kappa_{e} \nabla T_{e}-\mathbf{j} \cdot \mathbf{E}+\frac{3}{2} n_{e}\left(\mathbf{v}_{e} \cdot \nabla\right) k T_{e}+p_{e} \nabla \cdot \mathbf{v}_{e}$

where $\mathbf{j}$ is obtained from Eq. (3) after the plasma potential is calculated. Equation (6) is again a Laplace equation with weak source terms that is solved using the ADI approach. The transport coefficients are evaluated using the basic definitions from Ref. 18:

$$
\sigma=\frac{e^{2} n_{e}}{m_{e} v_{e}}
$$




$$
\kappa_{e}=\frac{2.4}{1+\frac{v_{e i}}{\sqrt{2} v_{e}}} \frac{k^{2} n_{e} T_{e}}{m_{e} v_{e}}
$$

where $v_{\mathrm{e}}=v_{\mathrm{ei}}+v_{\mathrm{en}}, v_{\mathrm{ei}}$ is the ion-electron collision frequency, $v_{\mathrm{en}}$ is the neutral-electron collision frequency, and these frequencies are evaluated for the xenon system using cross sections provided in Ref. 18.

The model calculations begin at the exit of the orifice nozzle. The flow conditions are estimated from the measured mass flow rate and current in addition to making assumptions for the species temperatures. In the present work, an electron temperature of $1.5 \mathrm{eV}$ is employed while the neutrals and ions are assumed to be at the cathode temperature of $1300 \mathrm{~K}$. The plasma density obtained in this manner is consistent with a detailed model of the hollow cathode insert and orifice regions developed by Domonkos. ${ }^{19}$

Boundary conditions are also required for plasma potential and electron temperature in the solutions of the current conservation (Eq. (4)) and electron energy (Eq. (6)) equations. The potential of the keeper is set along the surfaces of the keeper, and zero-gradient conditions are employed along all other boundaries, including the inflow plane. For electron temperature, an isothermal condition is used along the inlet plane and zero-gradient conditions are applied everywhere else.

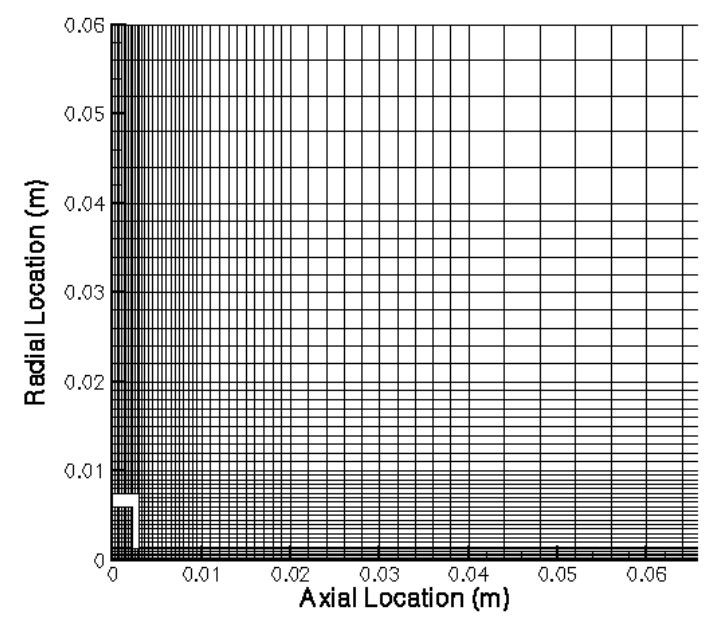

Figure 3. Detail of computational grid showing the orificekeeper and plume regions.

The computational domain extends to $0.25 \mathrm{~m}$ along the axis from the orifice and $0.25 \mathrm{~m}$ radially from the centerline. A portion of the grid is shown in Fig. 3 and employs 90 by 90 non-uniform, rectangular cells. A time-step of $5 \times 10^{-9} \mathrm{~s}$ is employed, which is smaller than the inverse plasma frequency. The simulation typically reaches a steady state after about 20,000 iterations and final results are obtained by averaging over a further 20,000 iterations. About 1.5 million particles are employed in each simulation.

The simulations are primarily performed for operating points 1 and 5. A primary goal of the numerical study is to investigate the sensitivity of the solutions to various assumptions employed for the boundary conditions and the physical state of the plasma. Assessment of the results is performed through comparisons with the measured data for current profile and ion energy distribution obtained with the RPA instrument. These data are recorded during the simulation at the same distance from the hollow cathode as in the RPA experiments (about $21 \mathrm{~cm}$ ).

\section{$\underline{\text { Results and Discussion }}$}

The test chamber pressure following a significant change in cathode operating point was found to vary substantially over a time scale of at least several minutes. The test chamber pressure is proportional to the mass flow rate exhausted by the cathode. The flow rate changes abruptly following an adjustment of the keeper current, returning slowly to its original equilibrium value. A change in heater current during the startup cycle requires a similar period of time to return to equilibrium. Figure 4 indicates the background pressure in the test chamber as a function of time following an increase of heater current from 1.7 to 2.0 A. The change is gradual throughout, as may be expected from a thermal phenomenon. The chamber pressure initially falls, presumably because the pressure elevation in the xenon gas behind the nozzle is constrained by the pressure in the cold gas reservoir of the supply line. Since the flow metering system supplies a constant flow into the reservoir, eventually the nozzle backing pressure will rise enough to again produce the original nozzle flow rate prior to the perturbation. If the nozzle backing pressure changes slowly compared to the temperature (due to the large size of the reservoir and low flow rate), an initial $\mathrm{T}^{-1 / 2}$ dependence in the test chamber pressure would be expected, where $\mathrm{T}$ is the stagnation temperature. ${ }^{20}$

When the keeper discharge switches on or off, the change in the background pressure of the vacuum chamber is large and immediate. This is followed by a slow return to the original level, on a time scale similar to that of Fig. 4. This observation suggests that the initial effect is nonthermal, whereas the subsequent drift toward equilibrium and return to the starting chamber pressure is either thermal or determined by the flow rate and rate of change in nozzle backing pressure.

Figure 5 indicates the step function in test chamber pressure and subsequent exponential decay 
that results from abrupt shutdown of the discharge at operating point 5 (OP5, see Table 1). It is likely that this behavior is associated with a flow impedance in the orifice when the discharge is on. Measurements on a T6 hollow cathode have revealed a complex variation of its back pressure with current and flow levels. ${ }^{7}$ Other measurements on xenon hollow cathode systems indicated that plasma and keeper potentials were similar in the gap between keeper and cathode orifice. ${ }^{10} \mathrm{~A}$ substantial voltage difference between plasma on opposite sides of the cathode orifice may therefore exist. The potential would then presumably have a large gradient in the vicinity of the outlet, and efficient ionization of the gas would occur in this region.

The formation of ionized xenon in the orifice and just outside will reduce the net xenon transport rate in the downstream direction if the electric field drives the ions upstream. In sufficient numbers, the change in net transport rate on turn-on could require a higher back pressure to re-establish the net downstream flow rate at the original level. In addition to their direct upstream migration in this picture, the ions will transfer momentum in the upstream direction to neutral xenon via collisions.

For this mechanism to be effective it is necessary to have high fractional ionization. An orifice current density $\geq 5 \times 10^{3} \mathrm{~A} / \mathrm{cm}^{2}$ at the flow rate of about 0.3 $\mathrm{g} / \mathrm{cm}^{2} \mathrm{~s}$ corresponds to an approximate electron efflux to atomic particle efflux ratio of $\geq 20$, and a high emission of doubly charged ions has been observed, ${ }^{5}$ suggesting that a high ionization fraction is generated in some region of the device.

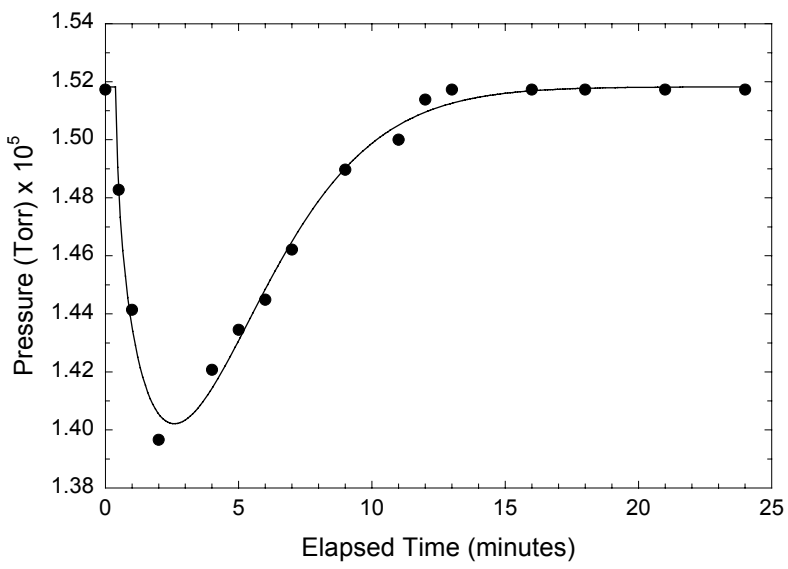

Figure 4. Test chamber pressure following an increase in cathode heater power from 1.7 to 2.0 Ampere (keeper supply off).

A mechanism involving the $\mathbf{j} \times \mathbf{B}$ force and a $\mathbf{z}$ pinch effect may alternatively, or in addition, serve to elevate the back pressure. ${ }^{7}$ The $\mathrm{z}$ pinch mechanism presumes a runaway increase in the $\mathbf{j} \times \mathbf{B}$ force below some critical flow rate or orifice pressure.
As a result of the flow impedance already discussed, the nozzle backing pressure builds up to a higher level in order to regain the flow rate through the nozzle as set by the flow metering system. The data of Fig. 5 suggest that the nozzle backing pressure during cathode operation was more than 4 times higher than under cold flow conditions. Upon startup, the vacuum chamber pressure drops immediately and is slowly regained over a similar time scale. The magnitude of the change in chamber pressure upon startup or shutdown seemed to decrease with accumulated cathode operating time as $V_{c k}$ decreased, and $I_{c k}$ operating point levels that were near the previous flow rate limits were more difficult to obtain, if they could be reached at all. This behavior may result from orifice widening due to gradual erosion.

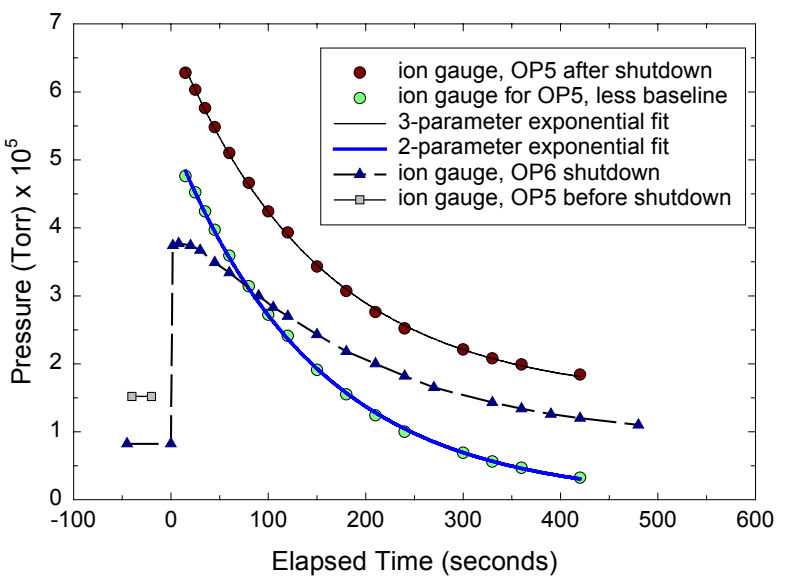

Figure 5. Test chamber pressure following shutdown of the keeper power supply. OP5 pressure exceeded OP6 because the cryopump was off.

In our previous study of the T5 hollow cathode, ${ }^{5}$ the mass spectrometer indicated a rapid initial rise in both $\mathrm{Xe}^{2+}$ and $\mathrm{Xe}^{+}$flux with increasing keeper current. However, above $\mathrm{I}_{\mathrm{ck}} \approx 1.3 \mathrm{~A}$ the $\mathrm{Xe}^{+}$flux decreased whereas $\mathrm{Xe}^{2+}$ continued to rise rapidly. Above $\mathrm{I}_{\mathrm{ck}} \approx 2.0$ $A$ the quartic relation describing $\mathrm{Xe}^{2+}$ flux also failed. While $\mathrm{Xe}^{3+}$ was sometimes detected at the highest $\mathrm{I}_{\mathrm{ck}}$ levels, the signal was always very weak.

The Saha equation is

$$
\begin{aligned}
& \frac{n_{e} n_{N-1}}{n_{N}}=2\left(\frac{2 \pi m k}{h^{2}}\right)^{3 / 2} \frac{u^{i}{ }_{N-1}}{u^{i}{ }_{N}} T^{3 / 2} e^{-I_{N} / k T} \\
& \cong 4.8 \times 10^{15} T^{3 / 2} e^{-I_{N} / k T} \mathrm{~cm}^{-3},
\end{aligned}
$$

where $n_{N-1}$ and $n_{N}$ are the densities of xenon ions with $\mathrm{N}-1$ and $\mathrm{N}$ electrons, respectively, the $\mathrm{u}^{\mathrm{i}}$ are their partition functions and $\mathrm{I}_{\mathrm{N}}$ is their ground state energy difference. From this expression can be obtained the 
electron temperature corresponding to a given charge state fraction under local thermodynamic equilibrium (LTE) conditions. For the case of $\mathrm{Xe}^{2+} / \mathrm{Xe}^{+}$, the population ratio at $\mathrm{n}_{\mathrm{e}}=10^{15} \mathrm{~cm}^{-3}$ is $17 \%$ with $\mathrm{kT}=1.2 \mathrm{eV}$ and $74 \%$ with $\mathrm{kT}=1.3 \mathrm{eV}$. At $\mathrm{kT}=2.0 \mathrm{eV}$ the dominant species is predicted to be $\mathrm{Xe}^{3+}$. LTE is a good assumption in this case only for more closely spaced energy levels, but the exercise does provide an indication that $\mathrm{T}_{\mathrm{e}}=1-2 \mathrm{eV}$ may be sufficient to produce the level of ionization observed.

The ion current collected by the RPA is shown in Fig. 6 as a function of keeper current at $F=0.10 \mathrm{mg} / \mathrm{s}$, for two angles with respect to the hollow cathode. The data show a sharp dependence on $\mathrm{I}_{\mathrm{ck}}$ at low levels, but the collected current is nearly constant at $\mathrm{I}_{\mathrm{ck}}=1.4 \mathrm{~A}$ and above. This observation is consistent with the approach to a fully ionized condition, as previously hypothesized. ${ }^{5}$ A first asymptote may be reached at $\approx$ 1.5A. The RPA current then appears to slowly rise for $\mathrm{I}_{\mathrm{ck}} \geq 1.8 \mathrm{~A}$. This behavior is not inconsistent with step ionization. Conversion from predominantly $\mathrm{Xe}^{+}$to $\mathrm{Xe}^{2+}$ could account for the apparently increasing RPA current at $\mathrm{I}_{\mathrm{ck}} \approx 2.0 \mathrm{~A}$. The absence of well-defined step behavior may result from a non-uniform distribution of ionization fraction in the gas and/or the fact that only a fraction of the ions are expelled through the keeper aperture.

The angular dependence of the ion current at several operating points is shown in Fig. 7 (see Table 1). The low-flow case corresponds to the highest peak. The angular full-width-half-maximum (FWHM) of that data is less than obtained for the high flow case. Visual observation of the hollow cathode indicated a more

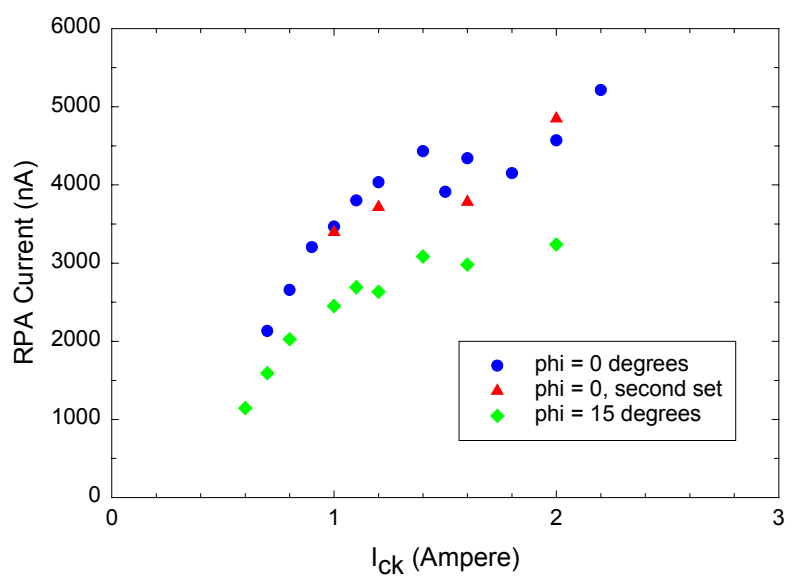

Figure 6. Dependence of normal-incidence RPA current on keeper current.

extended plume, about $3 \mathrm{~cm}$ long. The divergence therefore is pressure dependent and also possibly influenced by keeper potential, which was $33.8 \mathrm{~V}$ for the low-flow case and $26 \mathrm{~V}$ in the high-flow case.
Also shown is data for a medium-flow case, with substantially higher keeper current (operating point 6). Here the divergence is lowest despite a keeper potential of just $28 \mathrm{~V}$, consistent with the possible operation of a $\mathbf{j} \times \mathbf{B}$ pinch effect.

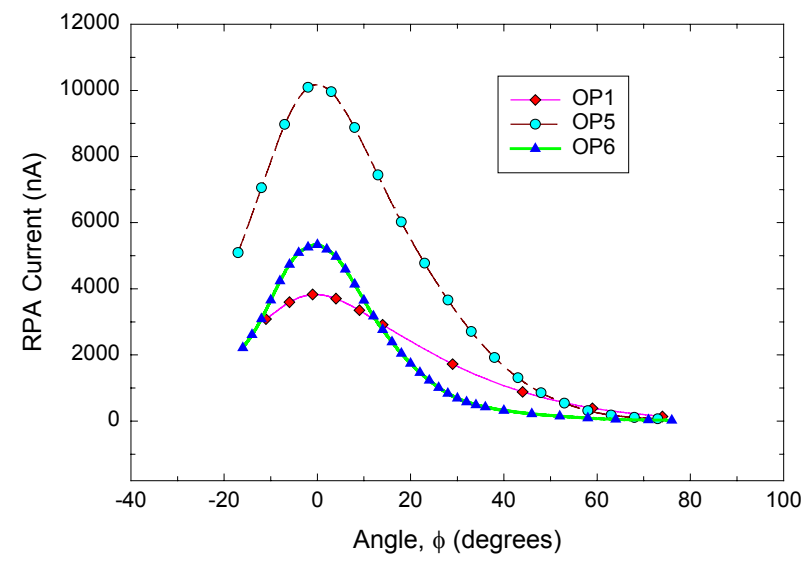

Figure 7. Angular distribution of ion efflux for several operating points.

The observed angular dependence of $\mathrm{Xe}^{2+}$ and $\mathrm{Xe}^{+}$at OP4 is plotted in Fig. 8, together with their uncorrected ratio. The $\mathrm{Xe}^{+}$flux has a FWHM of about 40 deg., in agreement with the RPA data for all ions at two different operating points (see Fig. 7). The $\mathrm{Xe}^{2+}$ flux decreases more rapidly with $\theta$, and therefore the $\mathrm{Xe}^{2+}: \mathrm{Xe}^{+}$ratio is less at larger $\theta$.

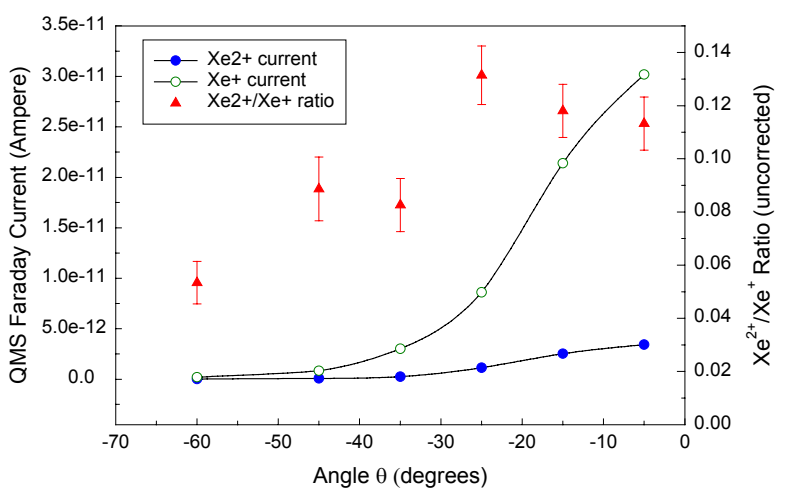

Figure 8. Relative ion flux levels and uncorrected charge ratio.

The $\mathrm{Xe}^{2+}: \mathrm{Xe}^{+}$ratio also decreases with $\theta$ for OP6, as shown in Figure 9. The $\mathrm{Xe}^{+}$relative flux recorded by QMS is also plotted, and its FWHM divergence is similar to the RPA result at the same operating point (see Fig. 7). The $\mathrm{Xe}^{2+}: \mathrm{Xe}^{+}$ratio was observed to be significantly greater at the highest discharge voltages (low flow rate and $\mathrm{I}_{\mathrm{ck}}$ ). 


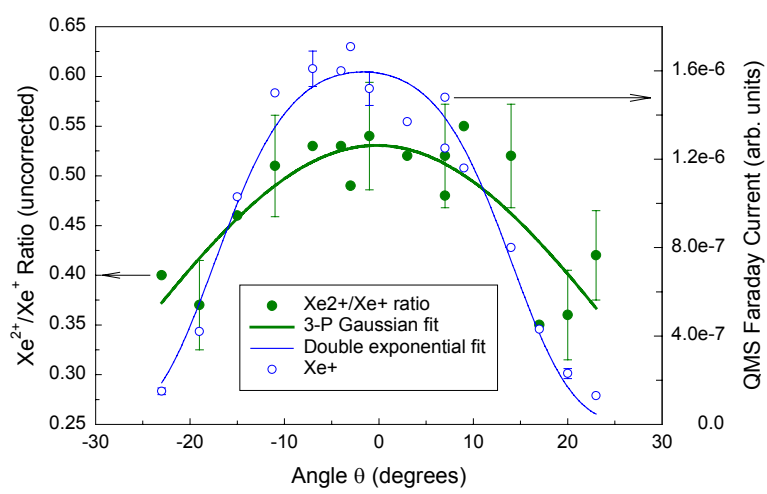

Figure 9. $\mathrm{Xe}^{+}$flux and uncorrected $\mathrm{Xe}^{2+}: \mathrm{Xe}^{+}$ratio as a function of $\theta$ for OP6, from QMS data.

Ion current emitted from the T5 hollow cathode was collected as a function of the RPA repeller voltage. The data of Fig. 10 were obtained for several operating points (see Table 1) and at several angles, $\phi=0^{\circ}, 15^{\circ}$ and $\approx 74^{\circ}$ between the RPA normal and the hollow cathode plume axis.

When viewing the hollow cathode at large $\phi$, the collected ion current is half-maximum at $\mathrm{V}_{\mathrm{r}}<20 \mathrm{~V}$. The plasma potential near the keeper (downstream side) may be expected to approximate $\mathrm{V}_{\mathrm{ck}}$, typically $25-30 \mathrm{~V}$. The majority of ions observed at $\phi=74^{\circ}$ were probably formed near the keeper aperture and driven out at

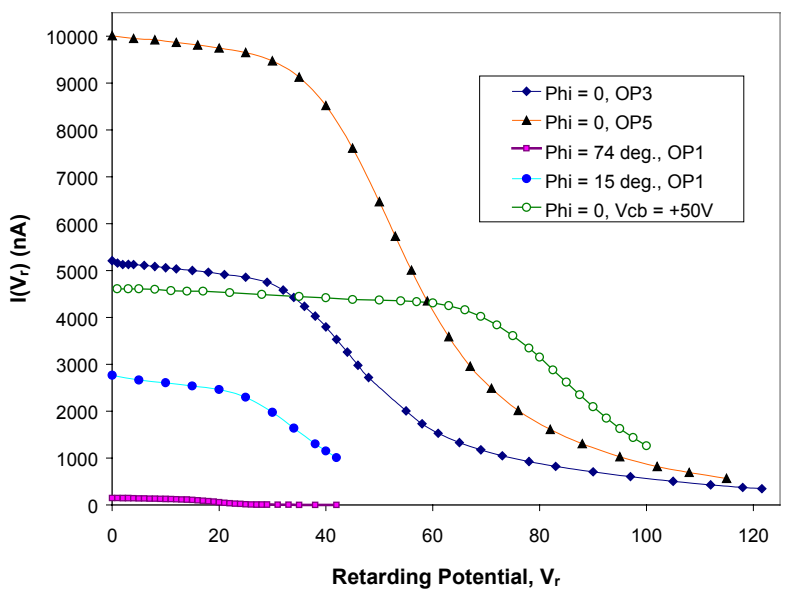

Figure 10. RPA current obtained as a function of repeller voltage at various operating points.

large $\phi$ by the local field. The quantity $\Delta \mathrm{I} / \Delta \mathrm{V}_{\mathrm{r}}$, plotted in Fig. 11, approximates the ion energy distribution. For $\phi=74^{\circ}$ the distribution peaks were found to be at 19 and $23 \mathrm{eV}$ for OP1 and OP2, respectively, consistent with the relative magnitudes of $\mathrm{V}_{\text {ck }}$. The major difference between OP1 and OP2 is flow rate. The ion flux at $\phi=74^{\circ}$ was approximately proportional to flow rate for these operating points. For the low pressure case the distribution goes to zero at $\mathrm{V}_{\mathrm{r}}=31$, about the value of $\mathrm{V}_{\mathrm{ck}}$. The high pressure case approaches zero at a

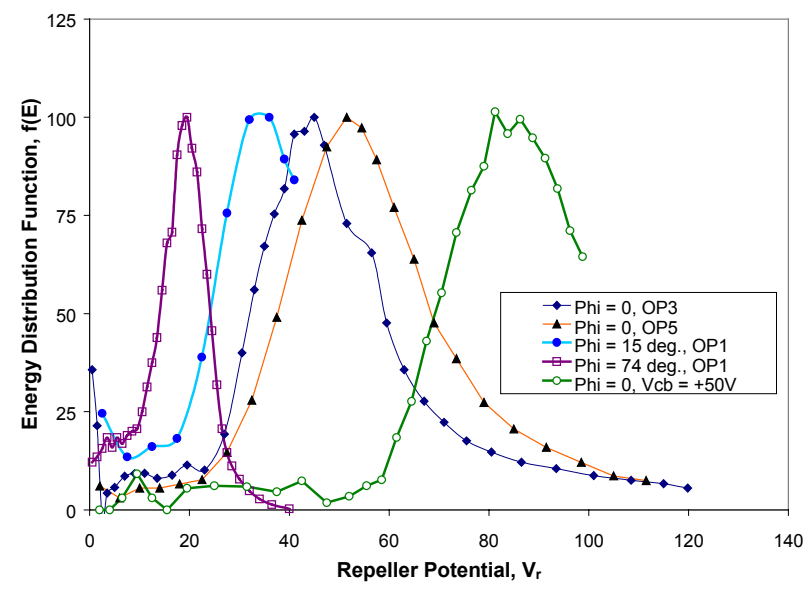

Figure 11. Derived energy distribution function at stated angle of incidence to RPA, for indicated operating points.

similar retarding potential, but here $V_{\text {ck }}$ was exceeded by a substantial amount. The ions at the high end of the distribution might also originate from $\mathrm{Xe}^{+}-\mathrm{Xe}$ scattering. In any case, the relatively low energy of observed energy distributions at large $\phi$ is consistent with formation via charge exchange, and subsequent migration along the local electric field gradient to the detector.

At small $\phi$ the ions are more energetic, as indicated by Fig. 11. Low flow rate is associated with relatively high-energy distributions, as is high discharge voltage.

\section{Comparison of Simulated and Measured Results Operating Point 1}

In Fig. 12, comparisons are provided between simulation and experiment for the ion energy distribution function close to the centerline. The baseline case assumes at the orifice that $\mathrm{T}_{\mathrm{e}}=\mathrm{T}_{\mathrm{i}}=1.5 \mathrm{eV}$, that the fraction of $\mathrm{Xe}^{2+}$ is $10 \%$ and that the potential at the orifice is $2 \mathrm{~V}$ less than the discharge potential. With these assumptions, the profile labeled "m2ev" is obtained. This profile gives excellent agreement with the location of the peak of the ion energy distribution but predicts a profile that is significantly narrower than that measured experimentally. In the simulation labeled "Xe2p", the fraction of $\mathrm{Xe}^{2+}$ is increased to $20 \%$ and this leads to modest increases in the peak and width of the distribution. For the results labeled "T2ev", we return to the baseline simulation but increase the plasma temperatures to $\mathrm{Te}=\mathrm{Ti}=2 \mathrm{eV}$ at the orifice exit. This change leads to a more significant increase in both the distribution peak and its width. Finally, in the 
simulation labeled "m6T2", the potential at the orifice exit is set to $6 \mathrm{~V}$ below the discharge potential and we set $\mathrm{T}_{\mathrm{e}}=\mathrm{T}_{\mathrm{i}}=2 \mathrm{eV}$. This simulation provides a distribution width that appears similar to the experimental data, but the peak of the distribution is now moved to about $25 \mathrm{~V}$ higher than the experimental data.

Results for the angular current profiles for these same 4 computations are compared with the RPA data in Fig. 13. In general, very good agreement with the data is obtained although the "m6T2" case under predicts the current and the "T2ev" case over predicts the current.

Profiles of electron temperature and plasma potential computed along the centerline are shown for three of the cases in Fig. 14. There is a simple, monotonic decrease of the electron temperature. The plasma potential shows a small hill close to the keeper location followed by monotonic decay and even falls below zero for two of the cases, thus explaining the high peak ion energies in those cases. In summary, the baseline case offers the best overall agreement with the RPA data although the predicted distribution is much narrower than the measured profile. Significant broadening of the distribution is predicted when the potential is decreased and the plasma temperatures increased at the orifice exit. However, this condition also leads to a reduction in current of about $40 \%$.

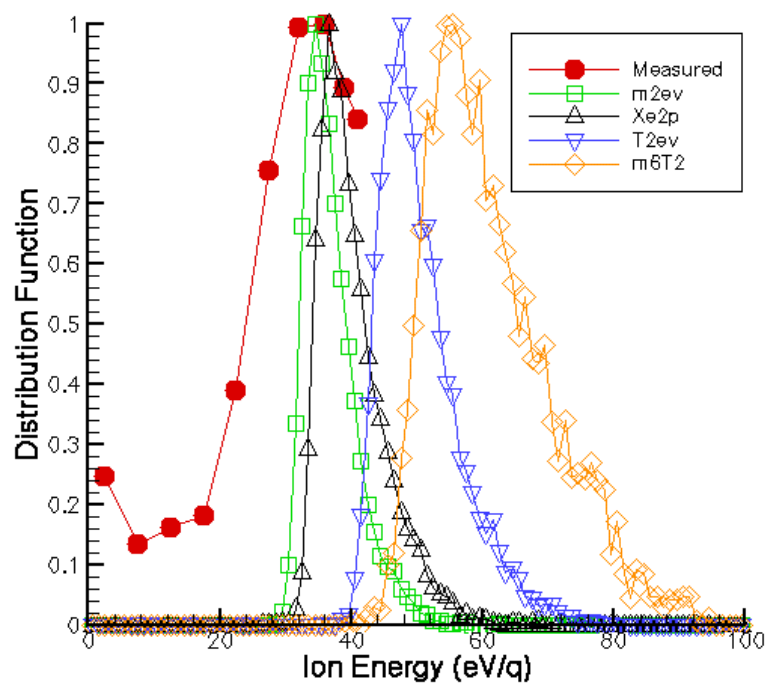

Figure 12. Ion energy distributions at the RPA position for Operating Point 1.

This trend is in qualitative agreement with Langmuir probe data obtained by Domonkos ${ }^{19}$ for a similar hollow cathode. A Langmuir probe measurement of centerline plasma potential and electron temperature of the present hollow cathode was performed at OP6, 35 $\mathrm{mm}$ downstream from the keeper. The values obtained were $7 \mathrm{~V}$ and $1.6 \mathrm{eV}$. Comparison of this data with onaxis simulation results is given in Fig. 15. The choice of $\mathrm{T}_{\mathrm{e}}=\mathrm{T}_{\mathrm{i}}=1.6 \mathrm{eV}$, potential $=\mathrm{V}_{\mathrm{ck}}-2$ at orifice exit, and $10 \%$ for the $\mathrm{Xe}^{2+}$ fraction produced good agreement.

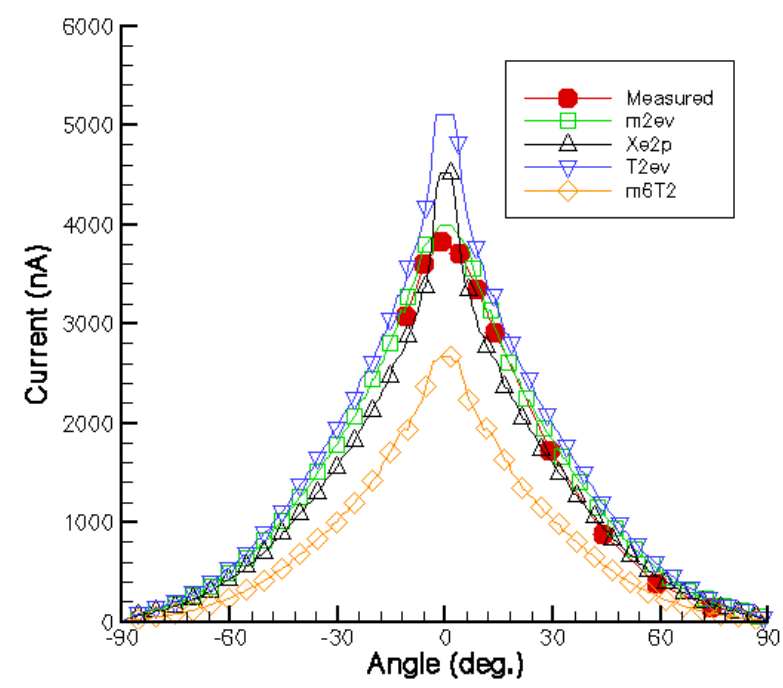

Figure 13. Angular current profiles at the RPA position for Operating Point 1.

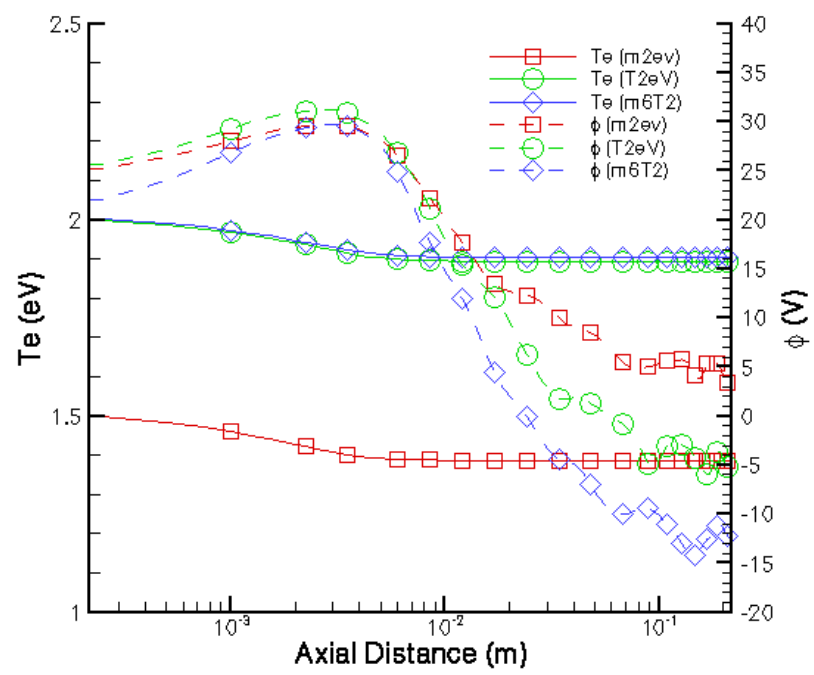

Figure 14. Computed plasma properties along the axis for Operating Point 1.

\section{Operating Point 5}

In Fig. 16, comparisons are provided between simulation and experiment for the ion energy distribution function close to the centerline. The baseline case assumes at the orifice that $\mathrm{T}_{\mathrm{e}}=\mathrm{T}_{\mathrm{i}}=1.5 \mathrm{eV}$, that the fraction of $\mathrm{Xe}^{2+}$ is $10 \%$ and that the potential at the orifice is $1 \mathrm{~V}$ less than the discharge potential. With these assumptions, the profile labeled "mlev" is 
obtained. By comparison with the measured data, this profile has a peak at a lower energy (22 eV lower) and is much narrower. As for the Operating Point 1 simulation results, the peak can be moved to higher energy by increasing the plasma temperatures at the orifice exit (labeled "T2ev"). Another way in which this can be accomplished in the simulation is to set the potential gradient to zero at the orifice exit. A

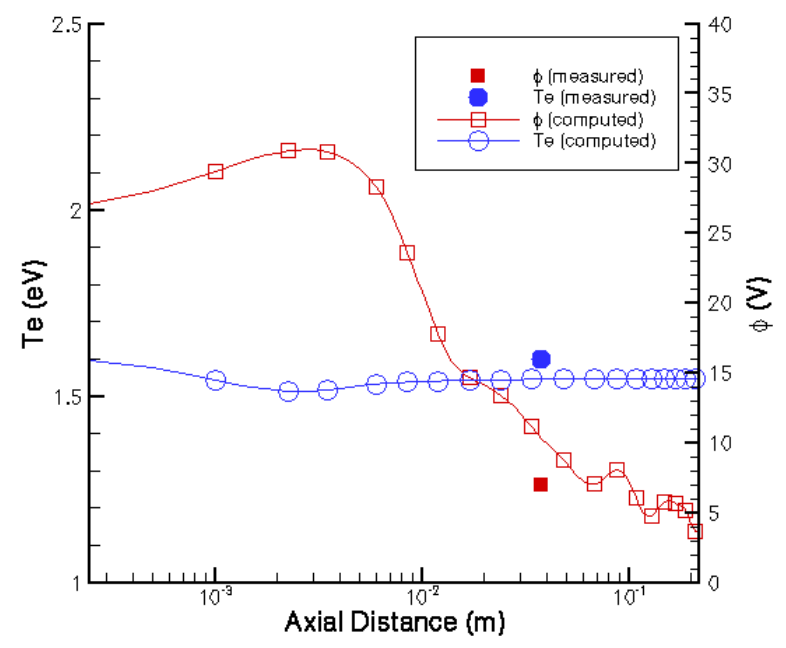

Figure 15. Langmuir probe data points and simulation results, on-axis for Operating Point 6.

simulation using this condition as well as a plasma temperature of $2 \mathrm{eV}$ is labeled "2TE0". The peak of this computation is very close to the measured value, but the width of the computed distribution remains significantly smaller than the measured profile. There

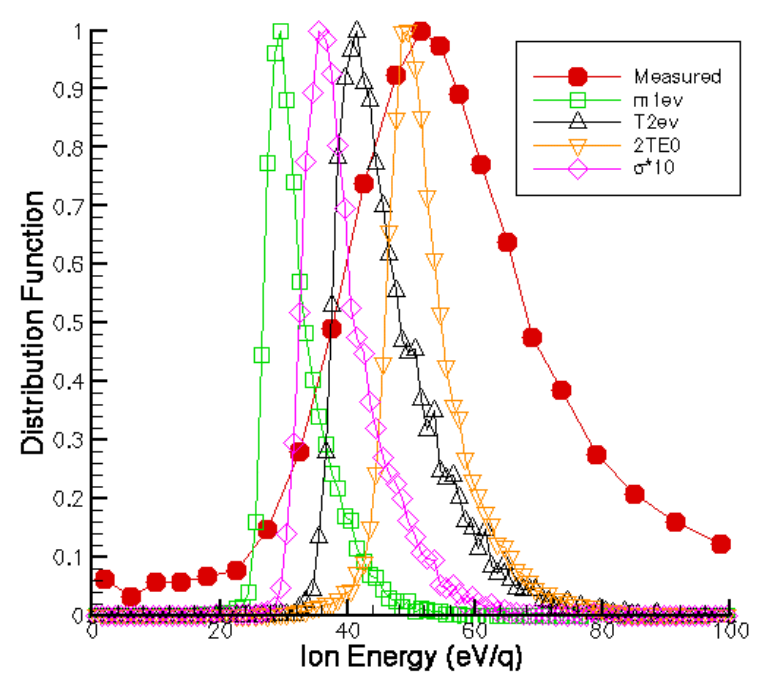

Figure 16. Ion energy distributions at the RPA position for Operating Point 5. has been discussion in previous modeling work on hollow cathode plumes (Ref. 15) of the possibility of anomalously high conductivity. To test this idea, the simulation labeled " $\sigma^{*} 10$ " uses the baseline conditions and increases the electrical and thermal conductivities by a factor of 10 . This condition leads to modest increases in both the peak and width of the computed distribution.

Results for the angular current profiles for these same 4 computations are compared with the RPA data in Fig. 17. In general, for this operating condition, there is very poor correspondence between the simulation results and the measured profiles. Most of the simulations under predict the current and predict a very peaked profile. The one exception is the "2TE0" case in which the current is actually over predicted.

The computed profiles of electron temperature and plasma potential are shown for 3 of the cases in Fig. 18. Both the "2TE0" and the "s*10" cases show first a decrease in temperature then a modest increase in temperature with distance along the centerline. Note that the "2TE0" case predicts a very high plasma potential at the orifice exit down which the ions accelerate to a peak energy close to that measured experimentally (see Fig. 16). However, it seems unlikely that such a potential could be supported at the orifice exit. In general, these simulations indicate that the predicted results vary significantly with the conditions assumed at the orifice exit. It is likely, by further variation of these conditions, that reasonable agreement could be obtained for both operating points. However, the more important conclusion is that accurate estimation of the conditions at the orifice exit

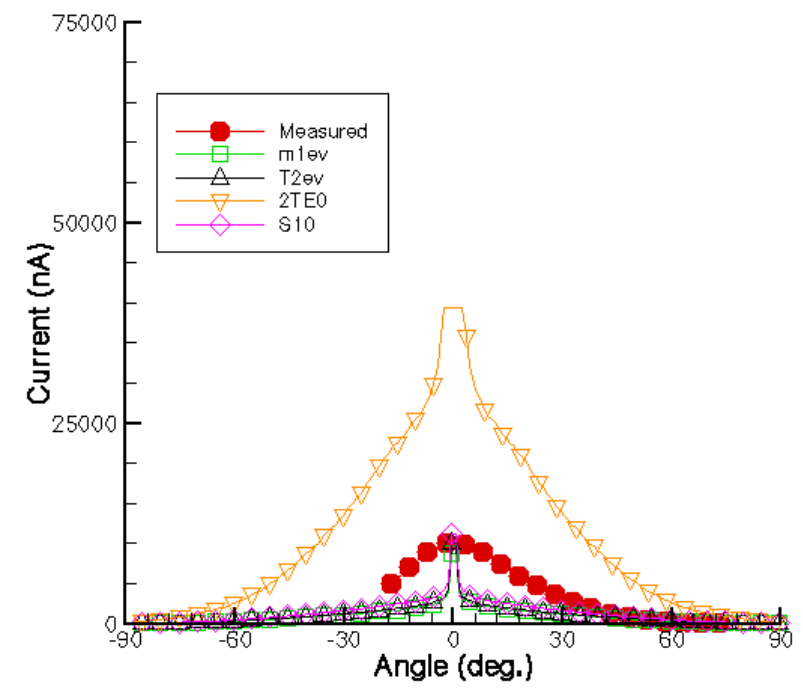

Figure 17. Angular current profiles at the RPA position for Operating Point 5. 


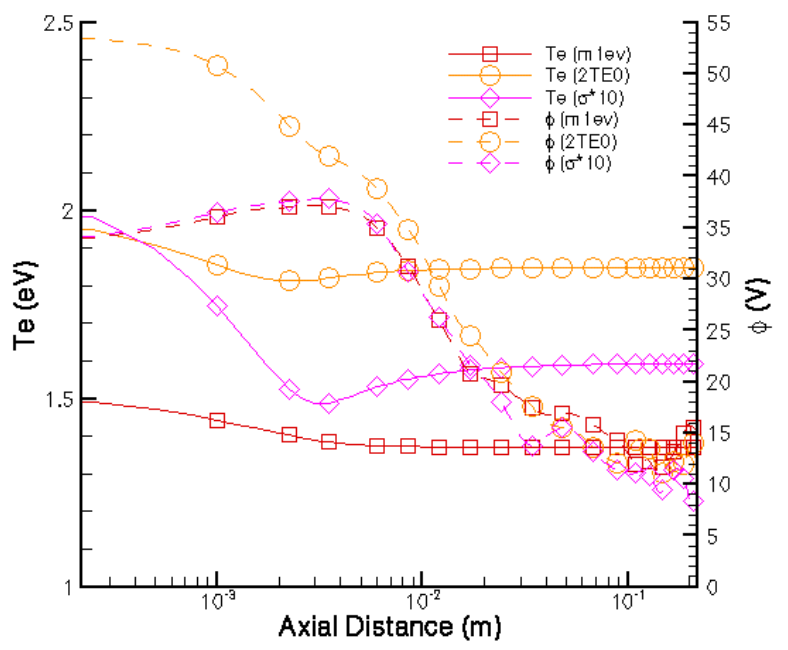

Figure 18. Computed plasma properties along the axis for Operating Point 5.

of the hollow cathode is required in order to more adequately assess the accuracy of the present hollow cathode plume model.

\section{Energy Distributions of the Ion Species}

Retarding potential data using the QMS as a filter of the mass to charge ratio are complicated by the variation of QMS transmission efficiency with ion energy. This variation, coupled with low signal level, produces a noisy spectrum. Since the transmission is highest at low ion energy, an apparent signal increase occurs just below the stopping potential for a given peak of incident ions (see Fig. 19). In the plot of $-\Delta \mathrm{I} / \Delta \mathrm{E}$ $(=\mathrm{f}(\mathrm{E}))$, a significant dip appears before each large peak as is apparent in Fig. 20. The species-specific energy distributions are very narrow at this condition. $\mathrm{Xe}^{+}$and $\mathrm{Xe}^{2+}$ have essentially identical distributions with respect to E/q, and two distinct peaks are apparent

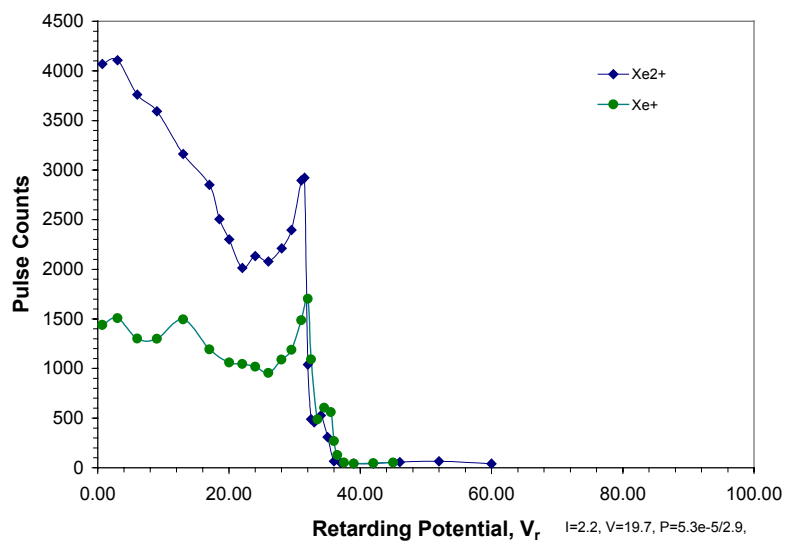

Figure 19. QMS ion flux for $I_{c k}=2.2 A, V_{c k}=19.7 V$, flow rate $=0.13 \mathrm{mg} / \mathrm{s}(\mathrm{OP} 7)$. for each. This means that $\mathrm{Xe}^{2+}$ has twice the kinetic energy of $\mathrm{Xe}^{+}$, to be expected if the energy was gained by simple acceleration through a potential difference. The presence of two peaks of similar E/q may imply that two distinct regions of slightly different potential exist, having high ion production rates. The operating condition (OP7) is one of high discharge current, low discharge voltage, and high flow rate. A 30\% reduction of discharge current results in a $30 \%$ increase in discharge voltage and dramatic broadening of the spectrum for both charge states, coupled with little if any divergence of the energy distributions (see Fig. 21). Due to the noise level of the derivative, considerable caution must be exercised in the interpretation of the $\mathrm{f}(\mathrm{E})$ spectrum. However, additional peaks seem to appear for each charge state, approximately at 6,16 , and $28 \mathrm{~V}$. A $30 \%$ reduction of flow rate results in a $20 \%$ increase in discharge voltage and broadening of the spectrum in a different way (see Fig. 22). This time

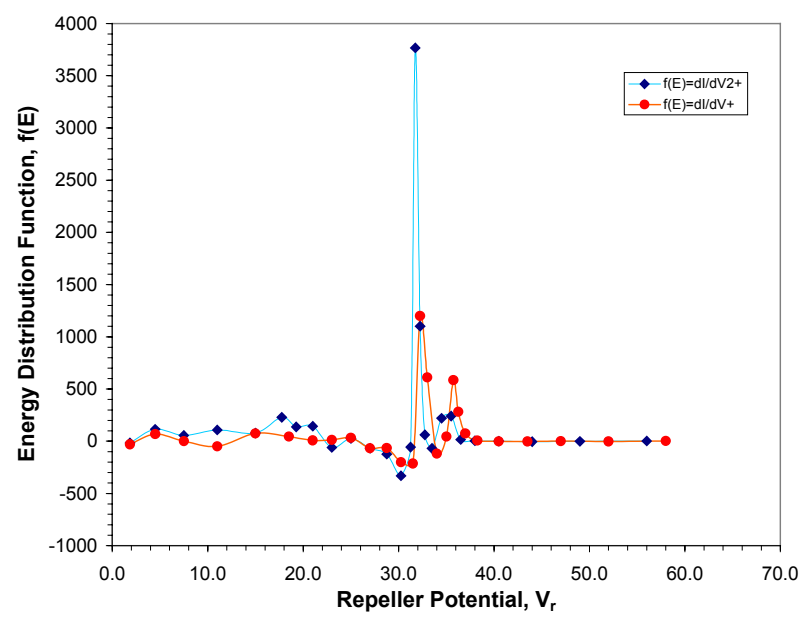

Figure 20. Measured axial energy distribution for $\mathrm{I}_{\mathrm{ck}}=2.2 \mathrm{~A}$, $\mathrm{V}_{\mathrm{ck}}=19.7 \mathrm{~V}$, flow rate $=0.13 \mathrm{mg} / \mathrm{s}(\mathrm{OP} 7)$.

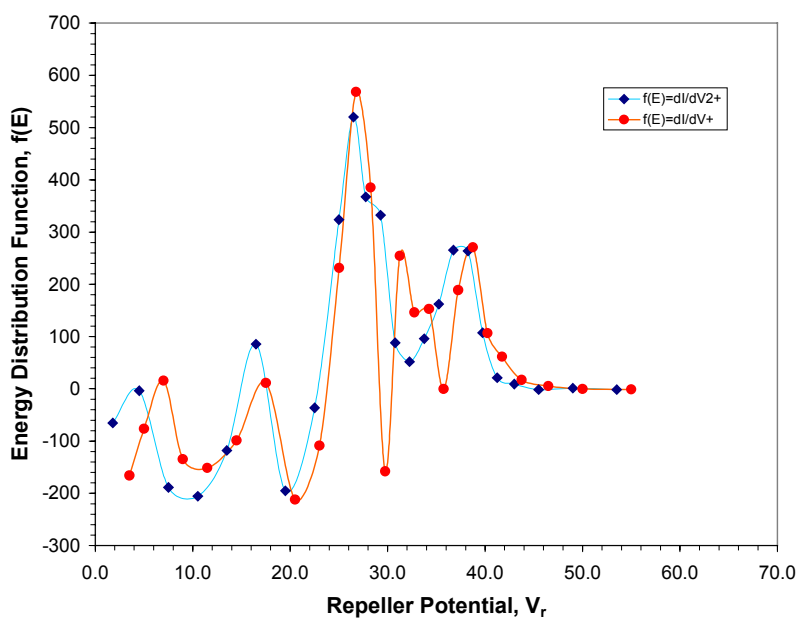

Figure 21. Measured axial energy distribution for $\mathrm{I}_{\mathrm{ck}}=1.77 \mathrm{~A}$, $\mathrm{V}_{\mathrm{ck}}=25.2 \mathrm{~V}$, flow rate $=0.13 \mathrm{mg} / \mathrm{s}(\mathrm{OP} 8)$. 


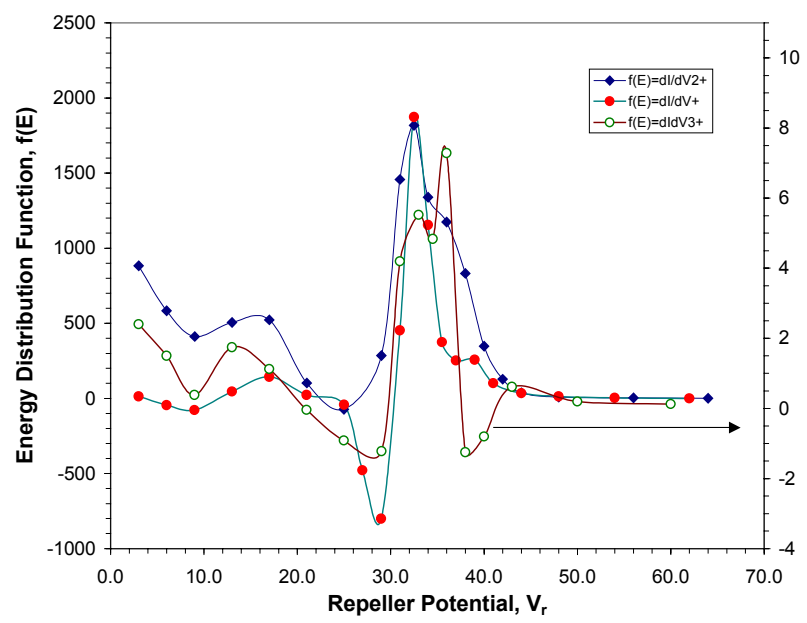

Figure 22. Measured axial energy distribution for $\mathrm{I}_{\mathrm{ck}}=2.20 \mathrm{~A}$, $\mathrm{V}_{\mathrm{ck}}=23.7 \mathrm{~V}$, flow rate $=0.10 \mathrm{mg} / \mathrm{s}$.

there seems to be just one new peak, a broad one at about $16 \mathrm{~V}$. The spectrum is similar but not identical for the three charge states investigated.

The discharge voltage was suppressed using cathode heater current for the data of Fig. 23. The energy distribution obtained at the same flow rate and similar discharge current but higher discharge voltage (heater current off, see Fig. 24), appears slightly wider, consistent with the trend of RPA data that low discharge current and high discharge voltage both correlate with broadened energy distributions. The discharge voltage seems to have the greatest influence. $\mathrm{V}_{\mathrm{ck}}$ was actually lower than obtained while taking the RPA data of Fig. 7, for similar cathode parameter settings of current and flow rate. For example, the data of Fig. 24 were obtained at OP1 with respect to current and flow rate, but $\mathrm{V}_{\mathrm{ck}}$ was $2 \mathrm{~V}$ too low. While this fact may help to explain the occurrence of obvious spectral structure in Fig. 24 and general lack of it in Fig. 7, it is not a sufficient explanation by itself.

Most ions will not pass from origination point to far-field plume without undergoing a collision. The QMS, particularly at such a large distance from the cathode, selects against ions involved in collisions - the requirements for incoming ions to be transmitted are stringent. In contrast, the RPA has a much larger acceptance angle. The relative number and type of collisions suffered by incoming ions may therefore be an important factor in determining the energy distribution. The various collision types have been discussed previously. ${ }^{21}$

Knowledge of the energy distributions for individual charge states is valuable for determining the validity of various models of proposed mechanisms for high-energy ion production in the hollow cathode plume. In the potential hill model, energy distributions will depend strongly on charge state $(\mathrm{E} \sim \mathrm{qV})$ and largely coincide when plotted vs. $\mathrm{V}_{\mathrm{r}}\left(\mathrm{V}_{\mathrm{r}}=\mathrm{E} / \mathrm{q}\right)$. In contrast, the gas dynamic model predicts the kinetic energy distributions will be similar for all ions. ${ }^{8,22,23}$

Other mechanisms may also operate to modify energy distributions. Recent data indicate the operation of rapid charge state conversion mechanisms in Hall thruster plumes. ${ }^{24}$ Hollow cathode plume measurements using a high resolution electrostatic analyzer also sometimes exhibit distinct peaks for which charge state conversion was a possible explanation. ${ }^{4,21}$ Charge state conversion will leave a distinct signature in the ion energy spectra, but this seems to be lacking in the present case. While there are differences in the energy spectra with respect to charge state, the similarity with respect to $\mathrm{E} / \mathrm{q}$ is striking and provides strong evidence

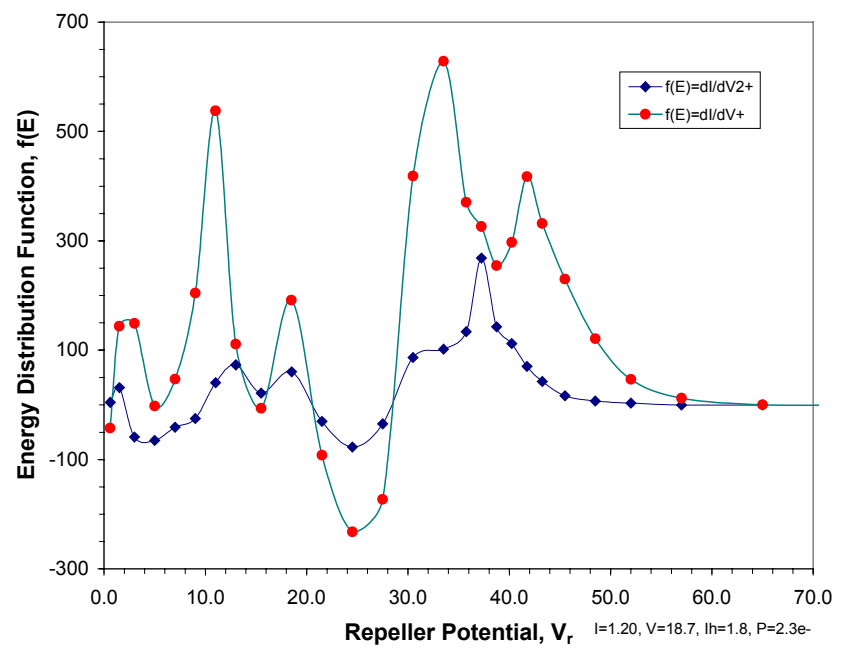

Figure 23. Measured axial energy distribution for $\mathrm{I}_{\mathrm{ck}}=1.20 \mathrm{~A}$, $\mathrm{V}_{\mathrm{ck}}=18.7 \mathrm{~V}, \mathrm{I}_{\mathrm{h}}=1.8 \mathrm{~A}$, flow rate $=0.10 \mathrm{mg} / \mathrm{s}$.

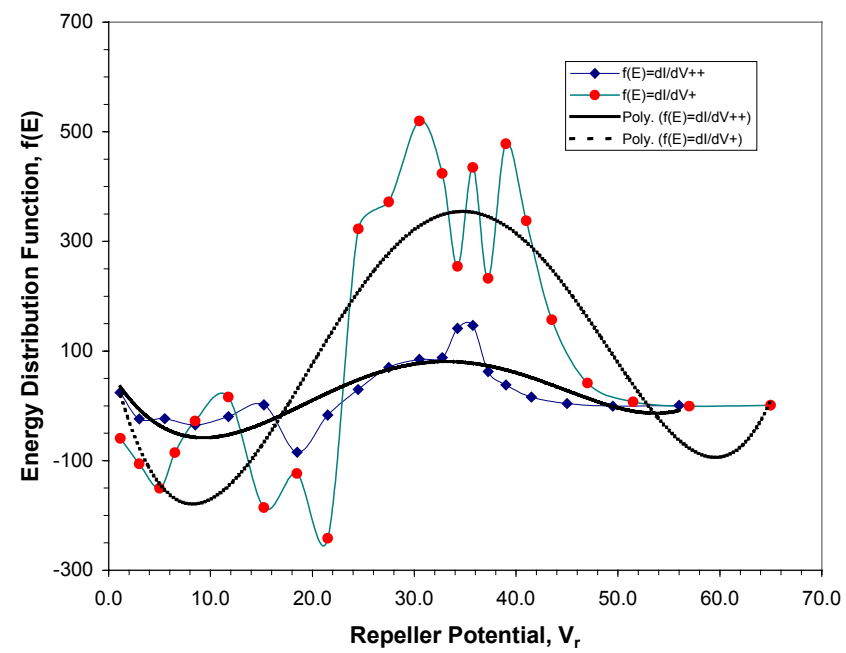

Figure 24. Measured axial energy distribution for $\mathrm{I}_{\mathrm{ck}}=1.12 \mathrm{~A}$, $\mathrm{V}_{\mathrm{ck}}=23.8 \mathrm{~V}$, flow rate $=0.10 \mathrm{mg} / \mathrm{s}$ (approximately OP1). 
for the dominance of electric potential in the determination of the ion energy spectrum. This result carries an implication for vacuum arc plasmas, where similar energy distributions are obtained from a discharge of about the same $\Delta \mathrm{V}$, that the acceleration may be primarily potential driven.

\section{Concluding Remarks}

A T5 hollow cathode has been characterized with respect to the far-field energy, angular, and flux distributions as a function of the ion charge state. These are the first xenon hollow cathode data obtained as a function of charge number.

Simulation with combined PIC and DSMC methods has produced results that can approximate the experimental ion flux and peak of the energy distribution. The principle discrepancy relates to the width of the ion energy distribution. The model predicts the existence of a small potential hill in the cathodekeeper gap, and plasma potential above the keeper voltage. Parameters utilized at the exit of the orifice were found to be highly influential but currently little is known about them experimentally.

The new results provide support for a potential hill model of ion acceleration, but the presence of multiple peaks implies a level of complexity not previously anticipated. The operation of other proposed mechanisms involving magneto-hydrodynamic, gas dynamic, and rapid charge conversion effects was not apparent. There are implications also for the muchstudied field of vacuum arcs, where debate has persisted for decades concerning the ion acceleration mechanism.

Table 1. Selected operating point data.

\begin{tabular}{ccccc}
\hline $\begin{array}{c}\text { Operating } \\
\text { Point }\end{array}$ & $\begin{array}{c}\text { Keeper } \\
\text { Current, } \mathrm{I}_{\mathrm{ck}}\end{array}$ & $\begin{array}{c}\text { Keeper } \\
\text { Voltage, } \mathrm{V}_{\mathrm{ck}}\end{array}$ & $\begin{array}{c}\text { Flow Rate, } \\
\mathrm{F}(\mathrm{mg} / \mathrm{s})\end{array}$ & $\begin{array}{c}\text { Test Chamber } \\
\text { Pressure (Torr) }\end{array}$ \\
\hline 1 & 1.12 & 26 & 0.10 & $1.4 \times 10^{-5}$ \\
2 & 1.16 & 29.8 & 0.030 & $4.3 \times 10^{-6}$ \\
3 & 1.00 & 31.8 & 0.030 & $4.3 \times 10^{-6}$ \\
4 & 1.20 & 25.9 & 0.10 & $1.4 \times 10^{-5}$ \\
5 & 1.30 & 34.0 & 0.045 & $6.8 \times 10^{-6}$ \\
6 & 1.77 & 28.2 & 0.054 & $8.8 \times 10^{-6}$ \\
7 & 2.20 & 19.7 & 0.13 & $1.8 \times 10^{-5}$ \\
8 & 1.77 & 25.2 & 0.13 & $1.8 \times 10^{-5}$ \\
9 & 1.12 & 23.1 & 0.13 & $1.8 \times 10^{-5}$ \\
\hline \hline
\end{tabular}

\section{Acknowledgments}

The preparation of this manuscript was supported by The Aerospace Corporation through its IRAD Program. IDB gratefully acknowledges Dr. Matt Domonkos of NASA Glenn Research Center for use of his hollow cathode analysis codes. MWC acknowledges J.E. Pollard for use of equipment and software related to acquisition of the Langmuir probe data. The hollow cathode was provided by D.G. Fearn and the Defence Evaluation and Research Agency.

\section{$\underline{\text { References }}$}

1. Kameyama, I., and Wilbur, P.J., "Zenith-Angle Distributions of Erosion Rates near High-Current Hollow Cathodes," AIAA Paper 96-3208, July 1996.

2. Latham, P.M., Pearce, A.J., and Bond, R.A., "Erosion Processes in the UK-25 Ion Thruster," IEPC Paper 91096, Oct. 1991.
3. Friedly, V.J., and Wilbur, P.J., "High Current Hollow Cathode Phenomena," J. Propulsion and Power, Vol. 8 (3), 1992, pp. 635-643.

4. Kameyama, I., and Wilbur, P.J., "Measurements of Ions from High-Current Hollow Cathodes Using Electrostatic Energy Analyzer," J. Propulsion and Power, Vol. 16, No. 3, 2000, pp. 529-535.

5. Crofton, M.W., "Preliminary Mass Spectroscopy of a Xenon Hollow Cathode," J. Propulsion and Power, Vol. 16, No. 1, 2000, pp. 157-159.

6. Kameyama, I., and Wilbur, P., "Potential-Hill Model of High-Energy Ion Production near High-Current Hollow Cathodes," ISTS Paper 98-a-2-17, 21st International Symposium on Space Technology and Science, Omiya, May 1998.

7. Patterson, S.W., and Fearn, D.G., "The Generation of High Energy Ions in Hollow Cathode Discharges," IEPC Paper 99-125, Oct. 1999.

8. Yushkov, G.Y., Anders, A., Oks, E.M., and Brown, I.G., "Ion Velocities in Vacuum Arc Plasmas," J. Applied Physics, Vol. 88, No. 10, 2000, pp. 5618-5622. 
9. Wieckert, C., "The Expansion of the Cathode Spot Plasma in Vacuum Arc Discharges," Physics of Fluids, Vol. 30, No. 6, 1987, pp. 1810-1813.

10. Williams, G.J. Jr., Smith, T.B., Domonkos, M.T., Gallimore, A.D., and Drake, R.P., "Laser Induced Fluorescence Characterization of Ions Emitted from Hollow Cathodes," IEEE Transactions on Plasma Science, Vol. 28, No. 5, 2000, pp. 1664-1675.

11. Crofton, M.W., "A Small Diagnostics Facility for Electric Propulsion Issues: Initial Hollow Cathode Results," AIAA Paper 99-0454, Jan. 1999.

12. Crofton, M.W., "Evaluation of the United Kingdom Ion Thruster," J. Spacecraft and Rockets, Vol. 33, No. 5, 1996, pp. 739-747, and references therein.

13. Crofton, M.W., "The Feasibility of Hollow Cathode Ion Thrusters: A Preliminary Characterization," AIAA Paper 2000-5354, July 2000.

14. Parks, D. E., Mandell, M. J., and Katz, I., "Fluid Model of Plasma Outside a Hollow Cathode Neutralizer," Journal of Spacecraft and Rockets, Vol. 19, 1982, pp. 354-357.

15. Williams, J. D. and Wilbur, P. J., "Electron Emission from a Hollow Cathode-Based Plasma Contactor," Journal of Spacecraft and Rockets, Vol. 29, 1992, pp. 820-829.

16. Birdsall, C. K. and Langdon, A. B., Plasma Physics Via Computer Simulation, Adam Hilger Press, 1991.

17. Bird, G. A., Molecular Gas Dynamics and the Direct Simulation of Gas Flows, Oxford University Press, 1994.

18. Mitchner, M. and Kruger, C. H., Partially Ionized Gases, Wiley, New York, 1973.

19. Domonkos, M. T., "Evaluation of Low-Current Orificed Hollow Cathodes," Doctoral Thesis, Department of Aerospace Engineering, University of Michigan, September 1999.

20. Miller, D.R., "Free Jet Sources," Atomic and Molecular Beam Methods, edited by G. Scoles, Vol. 1, Oxford, New York, 1988, pp. 14-53.

21. Crofton, M.W., and Boyd, I.D., "Plume Measurement and Modeling Results for a Hollow Cathode MicroThruster," AIAA Paper 2001-3795, July 2001.

22. Davis, W.D., and Miller, H.C., "Analysis of the Electrode Products Emitted by dc Arcs in a Vacuum Ambient," Journal of Applied Physics, Vol. 40, No. 5, 1969, pp. 2212-2221.

23. Tsuruta, K., Sekiya, K., and Watanabe, G., "Velocities of Copper and Silver Ions Generated from an Impulse Vacuum Arc," IEEE Transactions on Plasma Science, Vol. 25, No. 4, 1997, pp. 603-608.

24. Pollard, J., Diamant, K., Khayms, V., Glogowski, M., King, D., and de Grys, K., "Ion Flux, Energy, ChargeState Measurements for the BPT-4000 Hall Thruster," AIAA Paper 2001-3351, July 2001. 